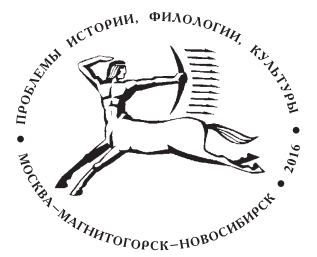

\title{
Племенной мир
}

Problemy istorii, filologii, kul'tury 2 (2017), 52-68

(C) The Author(s) 2017
Проблемы истории, филологии, культуры 2 (2017), 52-68 (с)Автор(ы) 2017

\section{ВОПРОСЫ МЕТАЛЛООБРАБОТКИ У КОЧЕВЫХ НАРОДОВ ЦЕНТРАЛЬНОЙ АЗИИ (РАННЕЕ СРЕДНЕВЕКОВЬЕ И ЭТНОГРАФИЧЕСКОЕ ВРЕМЯ)}

\author{
Г.Г. Король*, О.Б. Наумова** \\ * Институт археологии РАН, Москва, \\ ggkoro108@rambler.ru \\ ** Институт этнологии и антропологии им. Н.Н. Миклухо-Маклая РАН, Москва, \\ olganaumova@mail.ru
}

Аннотаиия. В статье поставлены вопросы, связанные с массовым распространением торевтики малых форм (ременной гарнитуры) у кочевников Центральной Азии в период возвышения Кыргызского каганата конца I тыс.: об источниках сырья, организации производства, сбыте продукции, ее распространении. Археологический материал из других регионов и хронологических периодов, например, Поволжья золотоордынского времени, показывает, что подобное производство существовало в оседлых поселениях, находившихся в тесных контактах с кочевой округой. Модель производства и распространения торевтики малых форм в Саяно-Алтае предполагает, что массовый спрос могли обеспечивать ремесленники, выходцы из городских центров Средней Азии с развитой традицией ремесленного мастерства. Близкая по стилю торевтика происходит из поселений Семиречья, в частности, Краснореченского городища, которое, к сожалению, исследовано с недостаточной тщательностью, чтобы судить о металлообрабатывающих мастерских, их профиле, возможной организации в городском пространстве. Таким образом, вопрос о центрах раннесредневекового металлического производства, поставлявших ременную гарнитуру кочевникам Саяно-Алтая, остается открытым.

Король Галина Георгиевна - кандидат исторических наук, старший научный сотрудник Института археологии РАН.

Наумова Ольга Борисовна - кандидат исторических наук, старший научный сотрудник Института этнологии и антропологии им. Н.Н. Миклухо-Маклая РАН.

Статья подготовлена при финансовой поддержке РФФИ, проект № 15-01-00306 (а).

(C) IA RAS, NMSTU, JHPCS, 2017 | DOI 10.18503/1992-0431-2017-2-56-52-68 
Этнографические данные о металлообработке у кочевых народов Центральной Азии и оседлого населения Средней Азии свидетельствуют о разных вариантах организации производства: в городских центрах, снабжавших и кочевую округу таких городов; в отдельных небольших мастерских самих кочевников, которые работали в основном на заказ. Реконструированная на археологических данных модель средневековой системы организации производства и распространения литых предметов художественной металлообработки в основных позициях не противоречит данным этнографии, но подтвердить ее могут только достоверные археологические свидетельства подобного производства.

Ключевые слова: торевтика малых форм, обработка металлов, организация производства, сбыт продукции, раннее средневековье, этнографическое время, кочевники, Центральная Азия

\section{Введение}

Во многом благодаря раннесредневековым кочевникам Центральной Азии мода на ременную гарнитуру определенных форм из цветного металла и прочие изделия торевтики малых форм получила распространение не только в степной зоне Евразии, но и у соседних оседлых народов. С первой трети VIII в. подобная гарнитура (накладки, подвески для конской сбруи, пояса всадников, детали оформления предметов вооружения и одежды) повсеместно стала украшаться декором нового облика (условно постсасанидского) с преобладанием растительного орнамента. Торевтика малых форм стала относительно массовым материалом в крупных регионах ее распространения 1 .

При исследовании культуры любой эпохи закономерно встают вопросы о производстве той или иной массовой категории изделий: источниках сырья, кем и как было организовано производство, как был налажен сбыт продукции, ее распространение, особенно если речь идет о значительных по размеру территориях ${ }^{2}$. Важно разрешить эти вопросы, когда рассматриваются процессы, происходящие в зоне контактов культур. Это относится и к чуть более раннему времени, например, выяснению вопросов организации производства украшений в стиле выемчатых эмалей для варварского населения Восточной Европы в римское время. Недавнее исследование ${ }^{3}$ отчетливо показало, что имело место массовое изготовление предметов позднеантичными мастерами на заказ согласно вкусам и эстетическим представлениям их потребителей. При этом ответить точно на вопрос, где же располагались эти производственные центры, не представляется возможным. Автор предлагает модель организации производства, находя аналогии в этнографическом материале близких территорий, не исключая, что, помимо производственных центров, отдельные античные мастера могли работать непосредственно в варварской среде.

\footnotetext{
1 Основные: Панония - Аварский каганат и культура венгров эпохи обретения родины; ЮгоВосточная Европа - Хазарский каганат; Центральная Азия - Тюркские каганаты, включая Уйгурский, Кыргызский и др.

2 См. Савинов 2006. Попытку наметить актуальные вопросы, касающиеся средневековых кочевников Центральной Азии и по-своему на них ответить, предлагая модель производства и распространения торевтики малых форм, см. Король, Конькова 2007.

3 Румянцева 2016.
} 
Задача статьи - на фоне краткого обзора археологических данных, позволяющих судить об организации металлообработки на примере производства и распространения торевтики малых форм в средневековье, обобщить информацию о тех же процессах в этнографическое время у кочевых и оседлых народов Центральной Азии и выяснить, насколько она может быть полезна для решения поставленных вопросов для средневековых культур.

$$
* * *
$$

Проблемы, связанные с производством ременных и других украшений в крупных регионах их распространения, решаются по-разному. Одни ученые пытаются реконструировать отдельные аспекты, например, способ производства у венгров эпохи обретения родины, прослеживая истоки и этапы его развития ${ }^{4}$. Другие, наоборот, на основе анализа не только ременных украшений, но и всего комплекса художественного металла, восстанавливают поэтапную историю развития прикладного искусства в целом, например, в Хазарском каганате ${ }^{5}$. Внимание уделяется многим аспектам: организации производства, стремлению к экономии металла ${ }^{6}$, разделению мастерских по статусу обслуживаемых заказчиков, разнице в материале и декоре изделий, возможных местах размещения мастерских; выделяется салтовский декоративный стиль, а также местная алано-болгарская ремесленная традиция.

Скрупулезное исследование технологии и декора древнерусских ременных украшений ${ }^{7}$ позволило выделить школы и центры производства ременной гарнитуры: «венгерскую или “позднехазарскую” школу»; «Волжско-болгарский» центр ${ }^{8}$; «Южный» центр (XI в.); «Черниговский» центр (вторая половина Х в.) и «скандинавскую» школу. Пути поступления цветных и драгоценных металлов выявлены на основе исследования химического состава изделий, в том числе ременных украшений; выделены основные источники: западно- и центральноевропейские рудники; Волжская Болгария; Арабский Восток; Византийская империя9 В период развитого средневековья (вплоть до конца XV - середины XVI в.) наборный пояс, сохранивший прежнюю структуру, продолжал существовать ${ }^{10}$.

\footnotetext{
4 László 1944, 353-358. На этой же территории в Аварском каганате популярная в VII в. штамповка сменяется в начале VIII в. литьем, что соотносят с новым населением и влиянием, пришедшим с востока (Erdélyi 1966, 34), хотя реконструкция технологии литья по восковой модели с использованием вставных сердечников (вставок) на предметах другой категории аварской эпохи детально описана (László 1972, 89-90) и связывается с достижениями эпохи переселения народов. Исследователь отмечает, что литые ременные украшения позднеаварской эпохи, возможно, делались именно таким способом, что позволяло литейщикам наладить реально массовое производство. «Большое преимущество этой процедуры в том, что не нужно вновь формовать сложный образец накладки, а только подправить его» (László 1974, 85). Важно отметить, что именно такая технология используется при изготовлении тюркских ременных украшений. Она требует мало металла и позволяет использовать в качестве матрицы саму накладку (подробнее см. Конькова, Король 1999, 59).

5 Фонякова 2009.

6 Для салтово-маяцкой археологической культуры характерны штампованные изделия в сочетании с литыми, а также серебряные поясные украшения, видимо, индивидуального заказа.

7 Мурашева 2000.

8 Волжская Болгария (г. Болгар) - известный центр производства не только ременной гарнитуры, но и многих других видов украшений из цветных и драгоценных металлов (Полякова 1996).

9 Коновалов, Ениосова, Митоян, Сарачева 2008, 155-162.

10 Мурашева 2000, 91-94, 97.
} 
Следует отметить, что только для развитого средневековья, золотоордынской эпохи (Улус Джучи), в Среднем и Нижнем Поволжье представлена универсальная модель соседства двух экономических миров: мира степных кочевников и оседлых сельскохозяйственных земель и городов с развитыми ремеслами. Имеющийся комплекс археологических данных позволяет прояснить, кто производил для кочевников изделия, снабжал их в том числе художественным металлом, изготовление которого требует опыта, подготовки и, главное - стационарных мастерских ${ }^{11}$. «Кочевники в обмен на продукцию скотоводства получали большой ассортимент ремесленных изделий, многие из которых в городах производились с учетом художественных вкусов и традиций номадов. Поступали к кочевникам и импорты» ${ }^{12}$.

Подобный симбиоз характерен и для регионов Центральной Азии, в первую очередь Средней Азии в тюркскую эпоху ${ }^{13}$. Саяно-Алтай представляет пока еще «темную» в этом отношении зону. В период середины IX-X в. (возвышение Кыргызского каганата) на данной территории зафиксирован буквально «бум» популярности ременных украшений с развитыми формами разнообразного декора при преобладании растительного. Вряд ли все это количество ременной гарнитуры попадало сюда только в качестве военной добычи вместе с воинами, возвратившимися из походов, или в качестве дипломатических даров. По археологическим материалам и письменным источникам известны торговые и дипломатические отношения каганата с ближними и дальними странами ${ }^{14}$, а также культурные влияния, которые прослеживаются по материалам торевтики малых форм ${ }^{15}$. Снабжение всадников необходимой гарнитурой, особенно в период походов, можно было обеспечить лишь при стабильном поступлении из каких-то производственных центров, мастерских городского ремесла. Упомянутая выше модель производства и распространения торевтики малых форм в Саяно-Алтае предполагает, что массовый спрос изделий не самого лучшего качества могли обеспечивать мастера-ремесленники - выходцы из городских центров Средней Азии с развитой традицией ремесленного мастерства, которые селились вдоль торговых путей в местах, приближенных к территориям непосредственного спроса на изготавливаемые изделия ${ }^{16}$.

«Ближайшими» к Саяно-Алтаю известными городскими центрами VIII-X вв., на которых условно «фиксируется» производство ременной гарнитуры с востребованным декором, можно считать города Семиречья в верховьях Чуйской долины Тянь-Шаня ${ }^{17}$ : городища Ак-Бешим, Красная Речка, Бурана и др., соответству-

11 Теоретически ответ на этот вопрос для одних очевиден, другие считают, что кочевники все делали сами, особенно там, где найдено много художественных изделий, но нет достоверных свидетельств местного производства (подробней о Саяно-Алтае см. Король, Конькова 2007, 29-30). Но, как известно, бронзовые изделия подвижны и долговечны: «они неоднократно меняют хозяев и перемещаются на значительные расстояния. Поэтому место находки в большинстве случаев не тождественно месту изготовления» (Беленицкий, Бентович, Большаков 1973, 287).

12 Недашковский 2014, 61. См. также: Недашковский 2010.

13 О взаимопроникновении и взаимообогащении культур Тюркских каганатов и оседлых цивилизаций Средней Азии см., например, Байпаков 2009.

14 Краткий обзор и литературу см. Король, Конькова 2007, 29, 30.

15 Король 2015.

16 Король, Конькова 2007, 28. По нашей модели, это лишь третий (из четырех) уровень качества изделий, но он самый массовый.

17 Байпаков, Терновая, Горячева 2007; Горячева 2010; Камышев 2012; Ведутова, Куримото 2014. 
ющие известным по письменным источникам городам Суяб, центр буддийской общины Семиречья VII-IX вв.; Невакет / Навекат («Новый город»), основанный переселенцами из Согда; Баласагун. Так, с городища Красная Речка происходит значительное число не только ременных и других украшений из цветного металла, но и свидетельства их местного производства: литейные заготовки, в том числе бракованные; готовые накладки с необработанными литниками, даже парные / тройные, соединенные литником; литники с частями пряжек; матрицы ${ }^{18}$; инструмент и приспособления ювелиров. К сожалению, почти все интересующие нас предметы с этого городища из случайных находок, в том числе грабительских. Справедливости ради надо отметить, что и археологами памятник исследовался совсем не так, как это можно было наблюдать на примере раскопок Пенджикента. Поэтому в публикациях о ремесле есть только общие слова и нет никакой информации о мастерских, их профиле, возможной организации в городском пространстве, как это воссоздано по материалам Пенджикента, исследованного с удивительной тщательностью и вниманием к любым мелочам. Так, отмечено, что топография ремесла в городе установлена прежде всего по металлообрабатывающему производству, в том числе бронзолитейному, поскольку мастерские имели стационарное оборудование и легко опознавались. Это позволило одному из авторов раскопок заключить, что ремесленник VII-VIII вв. был мелким товаропроизводителем, а наборные пояса изготавливались непосредственно в городах Согда ${ }^{19}$. В стационарных мастерских Пенджикента работали ремесленники - жители города; мастерские вне городской стены носили временный характер, здесь могли работать пришлые ремесленники ${ }^{20}$.

Наличие среди материалов из Краснореченского городища ременных украшений форм и стиля, близкого к изделиям с территории Саяно-Алтая; «туманные», но все же свидетельства местного производства части, а, возможно, и большинства из них, казалось, хоть как-то приблизят к положительным результатам поиска мест производства саяно-алтайских находок. Но нет. Знакомство с хорошими цветными фотографиями в публикациях, а также электронных источников стало поводом задуматься, а не было ли обратного влияния. Например, качество ${ }^{21}$ личин-подвесок и накладок, некоторые из которых изготовлены, казалось бы, по тем же образцам, что и саяно-алтайские находки, отличается от последних в худшую сторону. К ним «приделаны» какие-то звериные уши; на месте глаз, рта, иногда и носа - нарочитые отверстия ${ }^{22}$. Очевидно, что это не «портретные» изображения воинов, купцов, предков-охранителей и пр., по которым можно проанализировать даже антропологию представленных лиц ${ }^{23}$, а некие устрашающие маски, имею-

18 Судя по форме и декору, матрицы в основном относятся к II тыс. и характеризуют иную культуру.

19 Распопова 1980, 3, 130-131.

20 Распопова 1999, 11.

21 Речь идет только о декоре. Опыт изучения торевтики малых форм, в том числе состава металла, показал, что при очень плохом качестве декора металл мог быть очень хорошим. Это связано с технологией, позволяющей многократно репродуцировать предмет и его реплики. Можно предположить, что при массовом производстве в третьесортных мастерских уже не заботились о качестве декора или же не было соответствующих мастеров, способных качественно его подправить или же изготовить новую матрицу с хорошим рисунком.

22 Ср.: Горячева 2010, рис. 33 (справа внизу) и Король, 2008, табл. 12, рис. 3.

23 Король 2008, 108-112. 
щие совершенно иную содержательную подоплеку. Кроме того, исследователь комплекса торевтики малых форм разного времени с Краснореченского городища относительно зооморфных мотивов декора, некоторые из которых имеют ближайшие аналогии на Алтае, включая Восточное Прииртышье, считает, что они появились в Чуйской долине у карлуков под сильным влиянием кимаков, кыпчаков и других племен Алтая, а не наоборот. Отмечается и немногочисленность ременных украшений, выполненных в близкой, но не идентичной манере, присущей украшениям кыргызов, концентрированно живших в восточной части Саяно-Алтая на Среднем и Верхнем Енисее 24 .

Таким образом, имеющиеся археологические данные не позволяют решить ряд проблем, обозначенных во введении и связанных с массовым распространением в раннесредневековой Центральной Азии украшений из цветного металла, преимущественно ременных. Возможно, этнографические данные о традиционной металлообработке у кочевых и оседлых народов Средней Азии и Сибири, имеющих этногенетические связи с саяно-алтайским (южносибирским) средневековым населением, помогут приблизиться к решению поставленных вопросов. С этой точки зрения интерес представляет как организация, так и технология процесса обработки металлов.

$$
* * *
$$

Организация. Кочевники и полукочевники. У кочевых народов, как правило, кузнец и ювелир соединялись в одном лице. Мастер работал с железом, медью и изготовлял ювелирные изделия из серебра. Все процессы он выполнял сам - заготавливал уголь, сырье, готовил металл к обработке, выделывал изделия, проводил отделку. Более подробно о заготовке угля известно по киргизским материалам ${ }^{25}$. У каратегинских киргизов уголь для кузнеца выжигал заказчик ${ }^{26}$.

Народы Южной Сибири в этнографический период металл - медь, серебро, олово, железо - сами не добывали, а получали его от русских; серебро также и из Китая ${ }^{27}$. По имеющимся сведениям, лишь тувинцы до середины XIX в. для получения меди плавили руду ${ }^{28}$. Вероятно, также обстояли дела и у среднеазиатских кочевников: упоминается об изготовлении киргизскими кузнецами медных изделий, но где они брали медь, остается неясным ${ }^{29}$. Как правило, в качестве сырья мастера использовали вышедшие из употребления вещи, приобретенные на рынке или у заказчика ${ }^{30}$. У южных киргизов металлическое производство представлено только в двух видах - из железа и из серебра. Серебряные слитки покупали, часто заказчик приносил в качестве сырья старые вещи, также использовали серебряные монеты ${ }^{31}$.

Мастера у среднеазиатских кочевников работали в одиночку. Кузнец мог привлечь в качестве помощника сына или племянника, которому впоследствии пере-

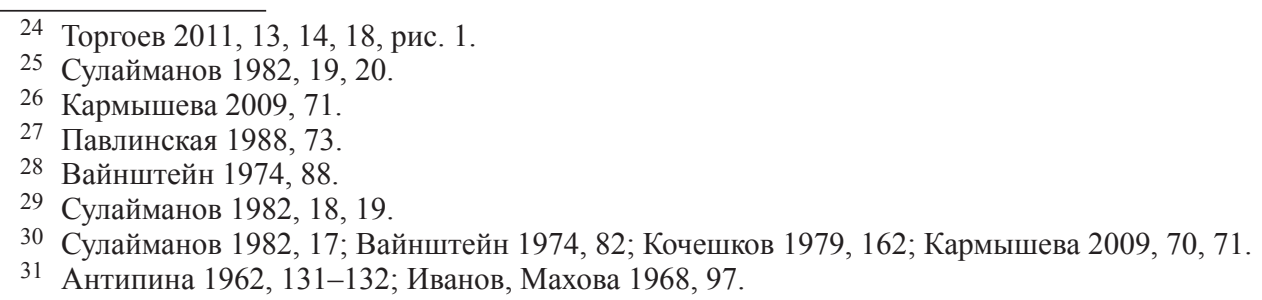


давал секреты мастерства. (Это же этнографы зафиксировали у тувинцев ${ }^{32}$.) Работал на заказ, изготовляя вещи для односельчан. Оплата труда была натуральной, у киргизов иногда применялась отработка ${ }^{33}$. Однако кое-где мастера (у монголов и бурят) могли производить вещи на продажу ${ }^{34}$. Ювелиры у оседлых туркмен также помимо работы по заказу продавали свои изделия на рынках ${ }^{35}$.

Помещением для работы у кочевников служил дом или юрта, в которой жил мастер по металлу. Иногда кузнецы делали навесы или работали в специальных юртах. Ювелиры же специальных помещений не имели. Занятие металлообработкой у монголов, тувинцев, киргизов не обеспечивало семью, поэтому кузнецы и ювелиры у кочевых народов продолжали вести традиционное для основного населения хозяйство ${ }^{36}$. Мастера у туркмен-полукочевников, занимавшихся земледелием, также совмещали свое ремесло с сельскохозяйственными занятиями; работали там же, где жили. Иногда ювелиры могли работать на дому у заказчика, питаясь вместе с его семьей ${ }^{37}$.

Исключением, вероятно, являются Забайкалье и Тува. Так как культовая пластика в ламаизме была связана с бронзой, то в этих районах в крупных дацанах существовали мастерские, которые «представляли собой центры сложного высокохудожественного литья» ${ }^{38}$. В данном случае, вероятно, необходимо говорить не о металлообработке у кочевников, а о ремесле в очагах оседлости, возникавших на территории обитания кочевых народов.

Таким образом, для тюркских и монгольских кочевников в этнографическое время характерны следующие черты организации металлообрабатывающих ремесел: мастера, как правило, владели и кузнечным, и ювелирным мастерством; работали в одиночку, в крайнем случае привлекая родственника в качестве помощника; работы мастер выполнял в основном на заказ за натуральную плату, в редких случаях для продажи в ближайшей округе; специально оборудованные помещения встречались нечасто ${ }^{39}$. Совокупность этих факторов свидетельствует о незначительных масштабах металлообработывающего производства у кочевников. Наладить систему обеспечения широкой территории однотипными металлическими изделиями только силами собственных мастеров при такой организации ремесла было бы проблематично.

Оседлое население. Качественно иной уровень организации ремесла существовал у оседлого населения Средней Азии. Это хорошо известно по исследованиям О.А. Сухаревой, посвятившей несколько работ ремесленной промышленности и цеховой организации позднесредневековой Бухары ${ }^{40}$; подобная организация ремесла была характерна и для других среднеазиатских городов. В Бухаре дей-

32 Сулайманов 1982, 66-67; Пиркулиева 1973, 55; Вайнштейн 1974, 84.

33 Антипина 1962, 132-133; Иванов, Махова 1968, 96; Пиркулиева 1973, 43; Вайнштейн 1974, 82; Кочешков 1979, 162.

34 Кочешков 1979, 24, 99.

35 Пиркулиева 1973, 42.

36 Антипина 1962, 132; Иванов, Махова 1968, 97; Вайнштейн 1974, 84; Кочешков 1979, 24; Сулайманов 1982, 64.

37 Пиркулиева 1973, 43.

38 Павлинская 1988, 73.

39 Сулайманов 1980, 92-93; 1982, 66-69.

40 Сухарева 1962; 1966; 1971. 
ствовало несколько цеховых корпораций мастеров по обработке металла: кузнецов, мастеров по литью чугуна, обработки меди, литью бронзы и ювелиров. И если у кочевников кузнец и ювелир, как правило, совмещались в одном лице, то у городских ремесленников существовала более узкая специализация внутри перечисленных корпораций, причем мастеров, совмещавших несколько узких специальностей, было немного ${ }^{41}$.

Заготовка угля и сырья для кузниц и литья металла также была более масштабной. Так, уголь для кокандских кузниц заготавливали киргизы в южных районах Киргизии ${ }^{42}$. В конце XIX - начале XX в. бухарские литейщики медь получали из России, ее поставляла фирма Вогау ${ }^{43}$. Плитки золота и серебра для ювелирных работ завозились в большом количестве также из России, а золото 100-й пробы, возможно, импортировалось какой-то гамбургской фирмой; серебро в слитках поступало и из Китая ${ }^{44}$.

У всех бухарских ремесленников были специальные мастерские, которые находились в определенных местах города ${ }^{45}$. Мастера имели нескольких помощников, особенно много работников было задействовано при отливке чугуна, ювелиры же могли работать и в одиночку. Количество ремесленников в городе в этот период было значительным: около 150 кузнецов, 40-50 бронзолитейщиков, до 400 ювелиров; в обработке меди было занято свыше 1000 человек (из них 400 мастеров $)^{46}$.

Городские ремесленники у оседлых народов работали на рынок, что не исключало работы и на заказ. Бухарские ювелиры и медники также работали и на двор эмира в государственных мастерских. Помимо мастерских, ремесленники имели в городе и торговые лавки в базарных рядах или специальных кварталах; там они продавали свою продукцию. Цехи кузнецов и ювелиров сами владели своими торговыми рядами, а продукция чугунолитейщиков и медников в конце XIX - начале XX в. в основном приобреталась скупщиками ${ }^{47}$.

Бухарские мастера снабжали своими изделиями город и окрестные селения; за ювелирными изделиями приезжали и из других городов, а продукция медников вывозилась во все города Средней Азии ${ }^{48}$. Интересно, что литейщики бронзы большую часть бронзовых пуговиц и колец отсылали в степь, «где на них был большой спрос у полукочевых узбеков и казахов» ${ }^{49}$. Работая на отдаленные рынки (для полукочевников), среднеазиатские городские ремесленники делали продукцию на их вкус: бухарские ювелиры, например, изготавливали «специальный товар» ${ }^{50}$.

\footnotetext{
41 Сухарева 1962, 31, 37, 40, 49.

42 Сулайманов 1982, 19-20.

43 Семья Вогау - российские предприниматели немецкого происхождения - владела, в частности, металлургическими предприятиями на Урале и монопольно торговала медью.

44 Сухарева 1962, 34-36, 43.

45 Мастерские литейщиков чугуна, как и во многих среднеазиатских городах, находились в самой старой части города, что свидетельствует о древности этого ремесла. (Ср. с определенным размещением в городе мастерских раннесредневекового Пенджикента.)

46 Сухарева 1962, 31-35, 37-38, 40, 50-51.

47 Сухарева 1962, 32, 33, 35, 37, 53-54.

48 Сухарева 1962, 33, 36, 41.

49 Сухарева, 1971, 158.

50 Сухарева 1962, 41. Вспомним описанные выше взаимоотношения городских центров с кочевой округой в Улусе Джучи на Волге. Следует заметить, что ременные украшения, попадавшие
} 
Сравнение организации металлообрабатывающего ремесла у кочевых и оседлых народов очевидно показывает, что массовое производство изделий из металла могло быть организовано только в условиях стационарных поселений. Причем оседлые ремесленники могли обеспечивать кочевников как нужным количеством предметов, так и их качеством - в соответствии с их эстетическими требованиями.

Технология. В отличие от декора и формы предметов, в частности, украшений, технологические приемы их изготовления вряд ли могут считаться надежным этническим индикатором, так как они могли легко заимствоваться, усовершенствоваться, трансформироваться и т.п. Однако, зная технику металлообработки, можно судить, насколько производство металлических предметов тем или иным способом могло обеспечить их массовость. С этой точки зрения и рассмотрим технологические методы кочевников и оседлого населения.

Кочевники. Центральноазиатские кочевники - монголы, буряты, тувинцы знали литье металлов. У тувинцев зафиксировано два способа литья: при помощи литейных форм, вырезанных из камня, и в глиняных формах, изготовленных путем выжигания деревянной модели. Последний был известен также бурятам и монголам ${ }^{51}$. У бурят существовал способ отливки в земляных формах $x \varpi^{52}$.

Эти и другие варианты литья бронзы у кочевых народов Южной Сибири подробно описывает Л.Р. Павлинская ${ }^{53}$, выделившая следующие способы: литье в каменную или корьевую форму; в глиняную или земляную форму по деревянной или костяной модели; литье по выжженной модели. Каменная форма для литья (изложница) после отливки сохранялась, и ее можно было использовать несколько раз. Литье в земляные формы по деревянной модели (у якутов и забайкальских бурят) с помощью опок - круглых или квадратных металлических обручей - позволяло использовать модель несколько раз, получая идентичные изделия.

Литье по выжженной модели практиковалось в основном у западных тувинцев и забайкальских бурят. Этот способ, в отличие от предыдущих, был одноразовым. Он считается более поздним, его истоки связываются исследовательницей с культурой средневекового оседлого населения Центральной Азии и Китая.

В каменных формах тувинцы отливали пуговицы, бляхи к свадебному головному убору, кольца, серьги и др., а в глиняных формах, которые затем разбивали, стремена, металлические части узды, украшения для сумок с огнивом, бронзовые рукоятки, ножи, части для деревянных ножен, футляры для иголок, статуэтки, шахматные фигурки, металлические бляхи для седел ${ }^{54}$.

Описаний техники литья бронзовых изделий у среднеазиатских кочевников практически нет. Главное внимание этнографы, собиравшие материал в 19501960-е годы, уделяли декоративной отделке металлических изделий, не углубляясь в технику их производства и лишь констатируя наличие литья наряду с другими технологическими процессами. Технику изготовления мелких литых металличе-

в Саяно-Алтай в раннем средневековье, определенно соответствовали вкусам владельцев. Из всего многообразия предлагавшихся композиций наиболее популярны были те немногие, смысловое содержание которых было понятно кочевникам и хорошо воспринималось в соответствии с мировоззрением и собственной культурой (подробней см. Король 2008, 157-176, 221-226).

51 Вайнштейн 1974, 87-88, 102.

52 Кочешков 1979, 104.

53 Павлинская 1988, 77-79.

54 Вайнштейн 1974, 87; Павлинская 1988, 79. 
ских предметов никто из исследователей не описывал. Еще в 1988 г. Л.Р. Павлинская с сожалением отмечала, что техника и технология обработки художественного металла выпадает из поля зрения исследователей. Сама она приводит информацию о способах литья у народов Южной Сибири ${ }^{55}$, но для кочевых народов Среднеазиатско-Казахстанского региона подобные описания отсутствуют.

Так, Э. Сулайманов сообщает, что киргизские мастера (как и буряты, тувинцы, хакасы, алтайцы, казахи, туркмены, башкиры, узбеки) «широко практиковали технику насечки или набивную таушировку - наложение серебра на поверхность железных пластин, которые в дальнейшем шли в основном для украшений предметов конского убора, мужских поясов, ножей, огнив, сундуков, футляров для чашек и др.» ${ }^{56}$. Накладные бляхи для отделки сбруи он называет в числе наиболее характерных видов изделий киргизского кузнечного производства ${ }^{57}$, однако нигде не описывает, как изготовлялись эти железные накладные пластинки.

Помимо литья в этнографическое время существовали и другие способы изготовления мелких металлических предметов, таких, как бляшки для конской сбруи. У туркмен и киргизов отделкой сбруи занимались ювелиры ${ }^{58}$. Упоминается о двух способах изготовления серебряных бляшек - штамповкой и литьем; приводятся рисунки «формы “калып” для штамповки (отливки) фигурных накладок», однако описания процесса литья нет ${ }^{59}$.

Киргизская техника штамповки мелких серебряных или медных бляшек для сбруи, а также женских украшений наиболее подробно описана С.В. Ивановым и Е.И. Маховой по полевым материалам последней ${ }^{60}$. Несколько по-иному штамповали мелкие серебряные бляшки туркменские мастера ${ }^{61}$.

Лакуны в описании технических приемов, применяемых кочевыми и полукочевыми народами для изготовления мелких медных и железных литых изделий, не дают возможности сделать конкретные выводы о преемственности или проследить эволюцию ремесла с раннесредневекового времени. Следует отметить, что литье в каменные и земляные формы, практикуемое в конце XIX - начале $\mathrm{XX}$ в. кочевниками и полукочевниками, давало технические возможности для относительно массового изготовления мелких предметов, как это зафиксировано для VIII-X вв. в Саяно-Алтае. Однако организация ремесла у этих народов не позволяла осуществить данную возможность, а техника литья в глиняных формах не могла обеспечить такого массового производства. Традиции штамповки / чеканки мелких изделий, фиксируемые в этнографическое время, - наиболее экономичный и простой способ изготовления. Он становится популярным и у кочевников

55 Павлинская 1988.

56 Сулайманов 1980, 94, 96.

57 Сулайманов 1982, 15-16. Заметим, что в средневековье в восточной части Саяно-Алтая, а именно в культуре кыргызов Среднего и Верхнего Енисея, в первой половине X в. началось постепенное замещение ременных украшений из цветного металла на железные с таушировкой серебром, которые стали «визитной карточкой» кыргызов развитого и позднего средневековья. При этом в западной части региона (на Алтае) бронзовые и серебряные украшения продолжали существовать до середины XI в., в Кузнецкой котловине они фиксируются и в XII в.

58 Пиркулиева 1973, 41; Антипина, 1962, 137.

59 Антипина 1962, 139, 141.

60 Иванов, Махова 1968, 99.

61 Пиркулиева 1973, 52. 
во II тыс., но в восточноевропейской зоне (Хазарский каганат) широко применялся и раньше наряду с литьем, о чем упомянуто выше ${ }^{62}$.

Оседлое население. Способы литья металлов городскими среднеазиатскими ремесленниками в конце XIX - начале XX в. описаны О.А. Сухаревой. Литье чугуна и бронзы были древними ремеслами, причем имели между собой много общего: «единый в принципе прием отливки расплавленного металла в формы, применение изложниц и песка для формовки, некоторые одинаковые термины» ${ }^{63}$. Так как предмет нашего исследования - средневековая бронзовая торевтика, в частности, украшения для сбруи, то имеет смысл подробно остановиться именно на бронзолитейном производстве в этнографическое время, тем более, что среднеазиатские литейщики бронзы изготовляли подобные предметы ${ }^{64}$. Описание даем по О.А. Сухаревой ${ }^{65}$.

Бронзолитейное производство имело свой цикл: пять дней велись подготовительные работы (подготовка топлива, сырья, форм), два дня отливали. Бронзу делали, сплавляя медь с оловом в соотношении $2: 1$ или 4:1. По другим сведениям соотношение было $3: 2$. Бронзу плавили в тиглях из огнеупорной глины. Тигли были одноразовыми: они сохраняли прочность, пока были на огне. Остывая, глина становилась хрупкой, и тигель рассыпался. На дно тигля клали кусочки олова, затем меди и бронзовый лом; ставили на горн и закладывали поверх углем. С огня тигель снимали щипцами с длинной ручкой.

Отливку производили в формы. Для этого имели парные прямоугольные бронзовые изложницы, наполнявшиеся песком, смешанным с клеем. В нем оттискивали форму отливаемого предмета, которую вырезали из дерева или алебастра: одну половину предмета в одной изложнице, а вторую - в ее паре. Затем все приготовленные изложницы ставились рядами и скреплялись железной цепью таким образом, чтобы образующееся при соединении половинок отверстие, куда лили бронзу, оказалось наверху. После отливки изделия обрабатывались напильниками.

К сожалению, более подробно способа отливки мелких предметов О.А. Сухарева не описывает. Она упоминает, что «для мелких поделок употреблялись специальные маленькие тигельки» 66 , вероятно, были и изложницы соответствующих размеров. Судить о том, насколько этот способ хорошо подходил для массового производства, тоже трудно. Исследовательница считает, что отливка предметов из бронзы в XIX - начале XX в. была одним из слаборазвитых промыслов. Существует мнение, что литье бронзы было утрачено среднеазиатскими народами чуть ли не в XIII в. ${ }^{67}$ Понять масштабы производства бронзолитейщиков во времена его расцвета, очевидно, можно, опираясь на общие черты в технологии литья бронзы и чугуна. В описываемый О.А. Сухаревой период литье чугуна в Бухаре было хорошо развито. Отливка производилась в каждой мастерской раз в два ме-

\footnotetext{
62 Подробней о преимуществах штамповки и других нетрудоемких техник, а также о переходе к изделиям из железа как прогрессивной экономной технологии см. Конькова, Король 1999, 63.

63 Сухарева 1971, 148.

64 Кроме бронзолитейщиков, пряжки и бляхи для поясов делали также медники, выковывая их из драгоценных металлов. Затем эти изделия декорировались ювелирами (Сухарева 1962, 39, 45).

65 Сухарева 1962, 38; 1971, 155-158.

66 Сухарева 1971, 155.

67 Сухарева 1971, 148, 155.
} 
сяца; до этого литейщики готовили нужное количество форм и занимались другой подготовительной работой. За один раз отливалось очень много изделий (например, лемехов сразу 1200 штук) ${ }^{68}$. При сходных технологиях и организации производства литье бронзы могло быть столь же масштабным.

Вероятно, после периода массового производства и распространения металлических изделий, фиксируемого в средневековье, наступил период упадка, а затем ремесло возродилось в примитивных формах. Так, по сведениям Н.В. Кочешкова, с 1691 по 1911 г. народные ремесла у монголов пришли в упадок. Металлообработкой занимались преимущественно в монастырях, куда приходили ювелиры и литейщики, выходцы из беднейших слоев народа. Лишь работы отдельных мастеров «свидетельствуют о том, что в области художественного литья монгольские мастера имели определенные навыки и вполне сложившиеся традиции, идущие еще от времени Кара-Корума (XIV в.), а может быть, и еще раньше» ${ }^{69}$. Причины упадка литья металла остаются неясными.

\section{$* * *$}

В самой общей форме можно говорить о преемственности способов металообработки в Центральной Азии с раннего средневековья. Но даже если сохранялась преемственность в технике и технологии металлообработки у кочевых народов региона с периода средневековья, это не приближает к ответу на вопрос о причинах исчезновения массового производства торевтики в начале II тыс. Ответ на него, видимо, надо искать не только в способах организации металообрабатывающего производства в средние века. На основании этнографических данных очевидно, что организация массового производства возможна только в условиях стационарных поселений. Возможно, что существовавшие среди раннесредневековых кочевников Центральной Азии или по соседству с ними очаги оседлости и были центрами массового изготовления торевтики малых форм. После их упадка по каким-то причинам ${ }^{70}$ организация ремесла в корне поменялась. Ремесло стало делом отдельных мастеров, что фиксируется в этнографическое время, когда производимых изделий было вполне достаточно, они не требовались в огромном количестве, как это было в тюркскую эпоху.

\section{Заключение}

Таким образом, собранные по крупицам этнографические данные весьма информативны для понимания проблем организации художественной металлообработки литых бронзовых изделий. Эти данные свидетельствуют о разных вариантах организации такого производства: в городских центрах с традициями ремесленного производства, снабжавших и кочевую близкую и дальнюю округу таких городов; в отдельных небольших мастерских самих кочевников, которые

68 Сухарева $1971,153-154$.

69 Кочешков, 1979, 24.

70 К таковым в первую очередь можно отнести политические перемены в Центральной Азии, связанные сначала с возвышением киданей в X в., вызвавшим новое массовое движение восточных племен на запад, что, по-видимому, отрезало восточную часть Саяно-Алтая (кыргызов) от мест производства художественных изделий, а затем и монгольскими завоеваниями, которые принесли упадок во всех сферах жизни их западных соседей. 
работали только на заказ и редко на продажу в соседних районах. Разработанная ранее модель средневековой системы организации производства и распространения литых предметов художественной металлообработки в основных позициях не противоречит данным этнографии, но подтвердить ее могут только достоверные археологические свидетельства подобного производства. Но таких свидетельств, даже по материалам исследованных городов Семиречья, которые можно было бы рассматривать как источник поступления продукции в регион Саяно-Алтая, пока нет. Теоретически, помимо городских центров, небольшие поселения ремесленников, прежде всего согдийцев, расселявшихся, как известно, далеко на восток от родины, на своем уровне также могли снабжать тюркских воинов средневековья ременными украшениями и другими изделиями художественной металлопластики из цветного металла.

\section{ЛИТЕРАТУРА}

Антипина, К.И. 1962: Особенности материальной культуры и прикладного искусства южных киргизов. По материалам, собранным в южной части Ошской области Киргизской ССР. Фрунзе.

Байпаков, К.М. 2009: Западнотюркский и тюргешский каганаты: тюрки и согдийцы, степь и город. Изв. Наи. АН Респ. Казахстан. Серия общественных наук 1 (268), 105-146.

Байпаков, К.М., Терновая, Г.А., Горячева, В.Д. 2007: Художественный металл городища Красная Речка (VI- начало ХІІІ в.). Алматы.

Беленицкий, А.М., Бентович, И.Б., Большаков, О.Г. 1973: Средневековый город Средней Азии. Л.

Вайнштейн, С.И. 1974: История народного искусства Тувы. М.

Ведутова, Л.М., Куримото, Ш. 2014: Парадигма раннесредневековой тюркской культуры: городище Ак-Бешим. Бишкек.

Горячева, В.Д. 2010: Городская культура тюркских каганатов на Тянь-Шане (середина $V I-$ начало ХІІІ в.). Бишкек.

Иванов, С.В., Махова, Е.И. 1968: Художественная обработка металла. В сб.: С.В. Иванов, Е.И. Махова (ред.), Народное декоративно-прикладное искусство киргизов. М., 96-122.

Камышев, А.М. 2012: Кыргызстан. В кн.: Ш. Пидаев (ред.), Художественная культура Центральной Азии и Азербайджана $I X-X V$ веков. T. III. Торевтика. Самарканд-Ташкент, 97-122.

Кармышева, Б.Х. 2009: Каратегинские киргизы. М.

Коновалов, А.А., Ениосова, Н.В., Митоян, Р.А., Сарачева, Т.Г. 2008: Цветные и драгоиенные металль и их сплавы на территории Восточной Европы в эпоху средневековья. М.

Конькова, Л.В., Король, Г.Г. 1999: Кочевой мир: развитие технологии и декора (художественный металл). ЭО 2, 56-68.

Король, Г.Г. 2008: Искусство средневековых кочевников Евразии. Очерки. Труды САИПИ V. М.- Кемерово.

Король, Г.Г. 2015: Культурные влияния в Центральной Азии и на сопредельных территориях рубежа I-II тыс. н.э. (по материалам торевтики малых форм). $P A$ 4, 64-77.

Король, Г.Г., Конькова, Л.В. 2007: Производство и распространение раннесредневековой торевтики малых форм в Центральной Азии. PA 2, 25-32.

Кочешков, Н.В. 1979: Декоративное искусство монголоязычных народов XIX - середины ХХ века. М.

Мурашева, В.В. 2000: Древнерусские ременные наборные украмения (X-XIII вв.). М. 
Недашковский, А.Ф. 2010: Золотоордынские города Нижнего Поволжья и их округа. М.

Недашковский, Л.Ф. 2014: Структура и внутренние связи округи золотоордынских городов Нижнего Поволжья. $P A$ 2, 48-61.

Павлинская, Л.Р. 1988: Некоторые вопросы техники и технологии художественной обработки металлов. В сб.: Ч.М. Таксами (ред.), Материальная и духовная культура народов Сибири. Л., 71-85.

Пиркулиева, А. 1973: Домашние промыслы и ремесла туркмен долины Средней Амударьи во второй половине XIX - начале $X X$ в. Ашхабад.

Полякова, Г.Ф. 1996: Изделия из цветных и драгоценных металлов. В кн.: Г.А. ФедоровДавыдов (ред.), Город Болгар: Ремесло металлургов, кузнецюо, литейщиков. Казань, $154-268$.

Распопова, В.И. 1980: Металлические изделия раннесредневекового Согда. Л.

Распопова, В.И. 1999: Металлические изделия из Пенджикента. СПб.

Румянцева, О.С. 2016: Украшения с полихромными эмалями из Брянского клада: техника изготовления и «авторство». $P A 4,16-29$.

Савинов, Д.Г. (ред.) 2006: Производственные ичентры: источники, «дороги», ареал распространения: мат-льк конф. СПб.

Сулайманов, Э. 1980: Киргизская традиционная металлообработка и ее этнографические параллели. СЭ 2, 92-102.

Сулайманов, Э. 1982: Традиции обработки металлов у киргизов. Фрунзе.

Сухарева, О.А. 1962: Позднефеодальный город Бухара кониа ХІХ-начала ХХ века. Ремесленная промышленность. Ташкент.

Сухарева, О.А. 1966: Бухара. ХІХ-ХХ вв. (Позднефеодальный город и его население). М.

Сухарева, О.А. 1971: К вопросу о литье металлов в Средней Азии. В сб.: Н.А. Кисляков (ред.), Занятия и быт народов Средней Азии. Л., 147-167.

Торгоев, А.И. 2011: Ременные украшения Семиречья V-начала ХІІІ в. (вопросы хронологии): автореф. дис. канд. ист. наук. СПб.

Фонякова, Н.А. 2009: Существовало ли хазарское искусство: доводы за и против. В сб.: Р.Р. Султанова (ред.), Искусство тюркского мира. Вып. 1. Истоки и эволюиия художественной культуры тюркских народов: материаль конференции. Казань, 124-132.

Erdélyi, I. 1966: L'art des Avars. Budapest.

László, G. 1944: $A$ honfoglaló magyar nép élete. Budapest.

László, G. 1972: L’art des Nomades. Paris.

László, G. 1974: The Art of the Migration period. Miami.

\section{REFERENCES}

Antipina, K.I. 1962: Osobennosti material'noi kul'tury i prikladnogo iskusstva yuzhnykh kirgizov. Po materialam, sobrannym v yuzhnoi chasti Oshskoi oblasti Kirgizskoy SSR [Features of the Material Culture and Applied Arts of Southern Kyrgyz. Based on Materials Collected in the Southern Part of the Osh Region of the Kirghiz SSR]. Frunze.

Baipakov, K.M. 2009: Zapadnotiurkskiy i tyurgeshskiy kaganaty: tyurki i sogdiytsy, step' i gorod [Zapadnoturk and Turgesh Kaganates: the Turks and Sogdians, the Steppe and the City]. Izv. Nats. AN Resp. Kazakhstan. Seriya obshchestv. nauk [Proceedings of the National Academy of Sciences of the Republic of Kazakhstan. Social Sciences series] 1 (268), 105-146.

Baipakov, K.M., Ternovaya, G.A., Goryacheva, V.D. 2007: Khudozhestvennyy metall gorodishcha Krasnaya Rechka (VI - nachalo XIII v.) [Artistic Metal of the Ancient Settlement Krasnaya Rechka (6 $6^{\text {th }}-$ the Beginning of the $13^{\text {th }}$ Century)]. Almaty.

Belenitskiy, A.M., Bentovich, I.B., Bol'shakov, O.G. 1973: Srednevekovyy gorod Sredney Azii [Medieval City of Central Asia]. Leningrad. 
Erdélyi, I. 1966: L'art des Avars. Budapest.

Fonyakova, N.A. 2009: Sushchestvovalo li khazarskoe iskusstvo: dovody za i protiv [Was there Khazar art: the Pros and Cons]. In: R.R. Sultanova (ed.), Iskusstvo tyurkskogo mira. Vyp. 1. Istoki $i$ evoliutsiya khudozhestvennoy kul'tury tyurkskikh narodov: materialy konferencii [The art of the Turkic world. Issue 1. Origins and Evolution of the Artistic Culture of the Turkic Peoples: Conference Materials]. Kazan, 124-132.

Goryacheva, V.D. 2010: Gorodskaya kul'tura tyurkskikh kaganatov na Tyan'-Shane (seredina VI - nachalo XIII v.) [Urban Culture of the Turkic Kaganates in the Tien Shan (Middle $6^{\text {th }}-$ Beginning of the $13^{\text {th }}$ Century) $]$. Bishkek.

Ivanov, S.V., Makhova, E.I. 1968: Khudozhestvennaya obrabotka metalla [Artistic Metal Working]. In.: S.V. Ivanov, E.I. Makhova (eds.), Narodnoe dekorativno-prikladnoe iskusstvo kirgizov [Folk Arts and Crafts of Kyrgyz]. Moscow, 96-122.

Kamyshev, A.M. 2012: Kyrgyzstan [Kyrgyzstan]. In: Sh. Pidaev (ed.), Khudozhestvennaya kul'tura Tsentral'noy Azii i Azerbaidzhana IX-XV vekov. Vol. III: Torevtika [Art Culture of Central Asia and Azerbaijan of the $9^{\text {th }}-15^{\text {th }}$ Centuries. T. III: Toreutics]. Samarkand-Tashkent, 97-122.

Karmysheva, B.Kh. 2009: Karateginskie kirgizy [The Kirgiz of Karategin]. Moscow.

Kocheshkov, N.V. 1979: Dekorativnoe iskusstvo mongoloyazychnykh narodov XIX - serediny XX veka [Decorative Art of Mongolian-speaking Peoples of the $19^{\text {th }}$ - the Middle of the $20^{\text {th }}$ Century]. Moscow.

Konovalov, A.A., Eniosova, N.V., Mitoyan, R.A., Saracheva, T.G. 2008: Tsvetnye i dragotsennye metally i ikh splavy na territorii Vostochnoy Evropy v epokhu srednevekov'ya [Non-ferrous and Precious Metals and their Alloys in the Territory of Eastern Europe in the Middle Ages]. Moscow.

Kon'kova, L.V., Korol', G.G. 1999: Kochevoy mir: razvitie tekhnologii i dekora (khudozhestvennyy metall) [Nomadic World: Development of Technology and Decor (Artistic Metal)]. Etnograficheskoe obozrenie [Ethnographic Review] 2, 56-68.

Korol', G.G. 2008: Iskusstvo srednevekovykh kochevnikov Evrazii. Ocherki [The Art of Medieval Eurasian Nomads. Essays]. Trudy SAIPI [Issues of the Siberian Association of Prehistoric Art Researchers] V. Moscow- Kemerovo.

Korol', G.G. 2015: Kul'turnye vliyaniya v Tsentral'noy Azii i na sopredel'nykh territoriyakh rubezha I-II tys. n.e. (po materialam torevtiki malykh form) [Cultural Influences in Central Asia and Adjacent Territories at the Turn of the $1^{\text {st }}-2^{\text {nd }}$ Millennia AD (on Materials of Small Toreutics)]. Rossiyskaya arheologiya [Russian Archaeology] 4, 64-77.

Korol', G.G., Kon'kova, L.V. 2007: Proizvodstvo i rasprostranenie rannesrednevekovoy torevtiki malykh form v Tsentral'noy Azii [Production and Distribution of Early Medieval Toreutics of Small Forms in Central Asia]. Rossiyskaya arheologiya [Russian Archaeology] $2,25-32$.

László, G. 1944: A honfoglaló magyar nép élete. Budapest.

László, G. 1972: L'art des Nomades. Paris.

László, G. 1974: The Art of the Migration period. Miami.

Murasheva, V.V. 2000: Drevnerusskie remennye nabornye ukrasheniya (X-XIII vv.) [Old Russian Belt Set Decorations $\left(10^{\text {th }}-13^{\text {th }} c c.\right)$. . Moscow.

Nedashkovskiy, A.F. 2010: Zolotoordynskie goroda Nizhnego Povolzh'ya i ikh okruga [The Golden Hord Cites of the Low Volga Region and their Periphery]. Moscow.

Nedashkovskiy, L.F. 2014: Struktura i vnutrennie svyazi okrugi zolotoordynskikh gorodov Nizhnego Povolzh'ya [Structure and Internal Relations of the Region of the Golden Horde Cities of the Lower Volga Region]. Rossiyskaya arheologiya [Russian Archaeology] 2, 48-61.

Pavlinskaya, L.R. 1988: Nekotorye voprosy tekhniki i tekhnologii khudozhestvennoy obrabotki metallov [Some Issues of Technology and Technology of Artistic Metalworking]. In: Ch.M. 
Taksami (ed.), Material'naya i dukhovnaya kul 'tura narodov Sibiri [Material and Spiritual Culture of the Peoples of Siberia]. Leningrad, 71-85.

Pirkulieva, A. 1973: Domashnie promysly i remesla turkmen doliny Srednei Amudar'i vo vtoroy polovine XIX-nachale XX v. [Domestic Handicrafts and Crafts of Turkmen of the Middle Amudarya Valley in the Second Half of the $19^{\text {th }}$ - Beginning of the $20^{\text {th }}$ Century]. Ashgabat.

Polyakova, G.F. 1996: Izdeliya iz tsvetnykh i dragotsennykh metallov [Products from NonFerrous and Precious Metals]. In: G.A. Fedorov-Davydov (ed.), Gorod Bolgar: Remeslo metallurgov, kuznetsov, liteyshchikov [City of Bolgar: Craft of Metallurgists, Blacksmiths, Foundrymen]. Kazan, 154-268.

Raspopova, V.I. 1980: Metallicheskie izdeliya rannesrednevekovogo Sogda [Metal Products of the Early Medieval Sogd]. Leningrad.

Raspopova, V.I. 1999: Metallicheskie izdeliya iz Pendzhikenta [Metal Products from Penjikent]. Saint-Petersburg.

Rumyantseva, O.S. 2016: Ukrasheniya s polikhromnymi emalyami iz Bryanskogo klada: tekhnika izgotovleniya i "avtorstvo" [Ornaments with Polychrome Enamels from the Bryansk Hoard: the Technique and "Authorship"]. Rossiyskaya arheologiya [Russian Archaeology] $4,16-29$.

Savinov, D.G. (ed.) 2006: Proizvodstvennye tsentry: istochniki, "dorogi", areal rasprostraneniya: materialy konferencii [Production Centers: Sources, "Roads", Distribution area: Conference Materials]. Saint-Petersburg.

Sukhareva, O.A. 1962: Pozdnefeodal'nyy gorod Bukhara kontsa XIX - nachala XX veka. Remeslennaya promyshlennost' [The Late Feudal City of Bukhara of the Late $19^{\text {th }}$ - early $20^{\text {th }}$ Century. Handicraft Industry]. Tashkent.

Sukhareva, O.A. 1966: Bukhara. XIX-XXvv. (Pozdnefeodal'nyy gorod i ego naselenie) [Bukhara. $19^{\text {th }}-20^{\text {th }}$ cc. (Late Feudal City and its Population)]. Moscow.

Sukhareva, O.A. 1970: K voprosu o lit'e metallov v Sredney Azii [On the Casting of Metals in Central Asia]. In: N.A. Kisliakov (ed.), Zaniatiya i byt narodov Sredney Azii [Occupations and Life of the Peoples of Central Asia]. Leningrad, 147-167.

Sulaymanov, E. 1980: Kirgizskaya traditsionnaya metalloobrabotka i ee etnograficheskie paralleli [Kyrgyz Traditional Metalworking and its Ethnographic Parallels]. Sovetskaya Etnogragiya [Soviet Ethnography], 2, 92-102.

Sulaymanov, E. 1982: Traditsii obrabotki metallov u kirgizov [Traditions of Processing Metals Among the Kyrgyz]. Frunze.

Torgoev, A.I. 2011: Remennye ukrasheniya Semirech'ya V-nachala XIII v. (voprosy khronologii): avtoref. dis. kand. ist. Nauk [Belt Decorations of the Semirech'e of the $5^{\text {th }}$ - the Beginning of the $13^{\text {th }}$ Century. (Questions of Chronology)]. Saint-Petersburg.

Vainshtein, S.I. 1974: Istoriya narodnogo iskusstva Tuvy [The History of Folk Art of Tuva]. Moscow.

Vedutova, L.M., Kurimoto, Sh. 2014: Paradigma rannesrednevekovoy tyurkskoy kul'tury: gorodishche Ak-Beshim [Paradigm of the Early Medieval Turkic Culture: Ancient Settlement Ak-Beshim]. Bishkek. 


\title{
ISSUES OF METALWORKING OF THE NOMADIC PEOPLES OF CENTRAL ASIA (EARLY MIDDLE AGES AND ETHNOGRAPHIC TIME)
}

\author{
Galina G. Korol'*, Ol'ga B. Naumova** \\ * Institute of Archaeology, Russian Academy of Sciences, Russia, \\ ggkorol08@rambler.ru \\ ** N.N. Mikloukho-Maklay Institute of Ethnology and Anthropology, Russian Academy of \\ Sciences, Russia, \\ olganaumova@mail.ru
}

Abstract. The article deals with the problems concerning the mass distribution of small-format toreutics (belt set) among nomads of Central Asia during the rise of the Kyrgyz Khaganate at the end of the $1^{\text {st }}$ millennium AD: sources of raw materials, organization of manufacture, sale and distribution of products. Archaeological material from other regions and chronological periods, for example from the Volga region of the Golden Horde time, shows that such a manufacture existed in sedentary settlements that were in close contact with the nomadic district. Model of production and distribution of small-format toreutics in the Sayan-Altai suggests that the mass demand could be provided by craftsmen who came from urban centers of Central Asia with a developed tradition of craftsmanship. A similar in style toreutics came from the settlements of the Semirechye, in particular the Krasnorechensky Fortified Settlement. Unfortunately, it has not been studied enough to judge the metalworking workshops, their profile and the possible organization in the urban space. Thus, the question of the centers of early medieval metal production that supplied the belt set to the nomads of Sayan-Altai remains open.

Ethnographic data on metalworking by the nomadic peoples and sedentary population of Central Asia indicate different variants of the organization of production: in urban centers, supplying nomadic districts of such cities: in separate small workshops of the nomads themselves, who worked mostly by order. The model of the medieval system for organizing the production and distribution of cast metal art objects reconstructed on archaeological data does not contradict the data of ethnography in basic positions, but it can be confirmed only by reliable archaeological evidence of such production.

Key words: toreutics of small forms, processing of metals, organization of production, market of products, early Middle Ages, ethnographic time, nomads, Central Asia 